\title{
The gap between medical and monetary choices under risk persists in decisions for others
}

\author{
Nathalie F. Popovic ${ }^{1}$ (D) Thorsten Pachur ${ }^{2} \quad$ Wolfgang Gaissmaier $^{3}$
}

\author{
${ }^{1}$ Graduate School of Decision Sciences and \\ Zukunftskolleg, University of Konstanz, \\ Konstanz, Germany \\ ${ }^{2}$ Center for Adaptive Rationality, Max Planck \\ Institute for Human Development, Berlin, \\ Germany \\ ${ }^{3}$ Social Psychology and Decision Sciences, \\ University of Konstanz, Germany

\section{Correspondence} \\ Nathalie F. Popovic, Social Psychology and \\ Decision Sciences, Department of Psychology, \\ University of Konstanz, P.O. Box 43, 78457 \\ Konstanz, Germany. \\ Email:nfpopovic@gmail.com

\section{Funding information} \\ German Research Foundation, Grant/Award \\ Number: FOR 2374; Graduate School of \\ Decision Sciences
}

\begin{abstract}
Decisions under risk in the medical domain have been found to systematically diverge from decisions in the monetary domain. When making choices between monetary options, people commonly rely on a decision strategy that trades off outcomes with their probabilities; when making choices between medical options, people tend to neglect probability information. In two experimental studies, we tested to what extent differences between medical and monetary decisions also emerge when the decision outcomes affect another person. Using a risky choice paradigm for medical and monetary decisions, we compared hypothetical decisions that participants made for themselves to decisions for a socially distant other (Study 1) and to recommendations as financial advisor or doctor (Study 2). In addition, we examined people's information search in a condition in which information about payoff distributions had to be learned from experiential sampling. Formal modeling and analyses of search behavior revealed a similarly pronounced gap between medical and monetary decisions in decisions for others as in decisions for oneself. Our results suggest that when making medical decisions, people try to avoid the worst outcome while neglecting its probability-even when the outcomes affect others rather than themselves.
\end{abstract}

\section{KEYWORDS}

decisions for others, decisions from experience, medical choices, monetary choices, risky choice

\section{INTRODUCTION}

A patient suffering from diabetes can choose between different medications to treat the condition. One of them leads, as a side effect, to diarrhea in $29 \%$ of patients. The other, equally effective as the first, leads to nausea in around $10 \%$ of patients. How do patients and doctors make such choices between treatments whose outcomes cannot be predicted with certainty, and are, therefore, decisions under risk? Traditionally, decisions under risk have been studied with choices between gambles involving monetary gains or losses. A common assumption arising from studies using monetary gambles is the maximization of expectation (Bernoulli, 1738/1954): People weight the outcomes of an option with their corresponding probabilities and choose the option that maximizes the expected value (EV). When faced with medical rather than monetary prospects, however, people seem to rely on a substantially different mechanism. Specifically, people often seem to neglect probability information and to rely on simpler, heuristic decision strategies (Lejarraga, Pachur, Frey, \& Hertwig, 2016; Pachur \& Galesic, 2013; Pachur, Hertwig, \& Wolkewitz, 2014; Suter, Pachur, \& Hertwig, 2016; Suter, Pachur, Hertwig, Endestad, \& Biele, 2015).

So far, research on medical decisions under risk and how they diverge from monetary decisions has been exclusively focused on decisions that people make for themselves. In everyday life, however, people often make medical and monetary decisions on behalf of or under the advice of somebody else. Financial managers, for example, choose investment options for their clients, but the anticipated gains and losses do not directly affect their own income but that of their client. Doctors recommend treatment options to their patients but do 
not have to deal with the potential side effects of the treatment themselves. Although patients are increasingly encouraged and enabled to play an active role in medical decision making, these decisions are still largely made by the doctors. Even if doctors only provide recommendations, these often determine the patient's final decision (Gurmankin, Baron, Hershey, \& Ubel, 2002).

In two studies, we investigated to what extent discrepancies between medical and monetary contexts also occur in decisions that affect others, with regard to both choice behavior and search behavior. Is the monetary-medical gap reduced in decisions for others relative to decisions for oneself? Or are medical decisions for others also more heuristic than monetary decisions, as has been found in decisions for oneself? Such a finding would be especially relevant for medical decision making, where doctors are usually expected to act as rational agents, making decisions by adequately weighing the risks and benefits of the treatment with the corresponding probabilities.

\subsection{Discrepancies between medical and monetary choices}

Differences in decision strategies and cognitive processes between choices with medical and monetary prospects have been systematically examined in several studies (Lejarraga et al., 2016; Pachur et al., 2014; Pachur \& Galesic, 2013; Suter et al., 2016, 2015). These studies suggest that in the medical domain compared with the monetary domain, people focus more on avoiding the worst outcome, largely disregarding the probability of the outcomes. Typically investigated in withinsubjects designs, participants make binary choices between monetary gambles (that could each lead to a monetary loss with some probability) and monetarily equivalent medical gambles (equally effective treatment options that could each lead to a different side effect with some probability). To equate the outcomes in both tasks in monetary terms, participants are asked in an initial evaluation task to indicate the amount they would be willing to pay to avoid each side effect of the medical gambles. This monetary evaluation task determines the monetary equivalents for each side effect for every participant. For every medical gamble, a corresponding monetary gamble is presented that features the same probabilities of both options, but where the side effects are replaced by participants' willingness to pay (WTP) to avoid the specific side effect. A medical gamble would be, for example, a choice between Medication A that could lead to memory loss with a probability of $19 \%$ and Medication $B$ that could lead to fever with a probability of $98 \%$. If the participant had indicated a WTP of $€ 150$ to avoid memory loss and a WTP of $€ 37.50$ to avoid fever, the same choice problem in the monetary domain would, hence, be a choice between monetary Option A that could lead to a loss of $€ 150$ with a probability of $19 \%$ and Option $B$ that could lead to a loss of $€ 37.50$ with a probability of $98 \%$.

Formal modeling and process data have shown that when choosing between options with medical outcomes, people's choices are often well described by the minimax heuristic (Savage, 1951). According to this heuristic, the option with the more attractive worst outcome is chosen-disregarding the probabilities. In the example above, the minimax heuristic would result in choosing Option B, as probabilities would be ignored and as fever is less bad than memory loss (as indicated by the participant's WTP to avoid each of the outcomes). In choices involving monetary losses, in contrast, people have been found to choose more often in accordance with the EV maximization strategy, which weights outcomes by their probabilities (Pachur et al., 2014). According to this strategy, one would choose Option A in the example above, as the EV would be higher $(-€ 150 * 0.19=-€ 28.50>-$ $€ 37.50 * 0.98=-€ 36.75)$. In line with differences in strategy use, systematic preference reversals have been shown between the medical and monetary domains for equivalent choice problems (e.g., to choose Option B in the medical domain but choose Option A in the equivalent choice problem in the monetary domain; Pachur et al., 2014).

To examine how people search for information in both domains and how important it is for them to obtain precise knowledge about the probabilities of specific outcomes, Lejarraga et al. (2016) tested participants' search and decision behavior in a decisions-from-experience (DfE) paradigm (e.g., Hertwig, Barron, Weber, \& Erev, 2004; Kellen, Pachur, \& Hertwig, 2016) In this paradigm, participants initially do not have any information about the payoff distribution of each option; they only see two buttons on the screen representing the two different options. Participants can learn about the outcomes and probabilities by sampling from each of the options without any cost. Clicking on Option A, for example, triggers a random draw of an outcome from Option A's outcome distribution. Participants are told that they can sample as often as they like from each option before making a decision. People who mostly care about the outcomes are expected to sample much less often compared with people who are also interested in the probabilities of each outcome. In line with conclusions from people's choice behavior, the authors found that people sampled less frequently for medical than for monetary gambles. In a similar vein, data from a process-tracing study showed that people distribute their search effort equally among outcome information and probability information in the monetary domain but look less at probability information than at outcome information in the medical domain (Pachur et al., 2014).

One explanation provided for the discrepancy between medical and monetary decisions is the affective content of the different prospects: Compared with monetary outcomes, medical side effects are often associated with a stronger affective response, which could explain the stronger focus on outcomes in the medical domain (Pachur et al., 2014). Also other studies have suggested that affect-rich outcomes lead to a neglect of the corresponding probabilities (Petrova, van der Pligt, \& GarciaRetamero, 2014; Rottenstreich \& Hsee, 2001; Sunstein, 2003). The discrepancy in decision behavior between monetary and medical decisions has therefore been referred to as the affect gap (Pachur et al., 2014).

\subsection{Decisions for another person}

To date, research on the discrepancy between monetary and medical choices has exclusively focused on decisions for oneself. Will medical and monetary decisions also differ when the choices are made for others, and will decision strategies and search behavior diverge? To 
the best of our knowledge, there are no studies investigating decision processes in risky choices made for others in the medical and monetary domains, but we can derive three possible scenarios from the existing literature: (a) People make more defensive decisions for others and deviate more strongly from rational norms, independent of choice domain (main effect of decision perspective), (b) people make more rational decisions for others, independent of choice domain (main effect of decision perspective), and (c) the gap between medical and monetary choices decreases in decisions for others (interaction between decision perspective and choice domain). We next describe these possible scenarios in more detail.

\subsubsection{More defensive decisions for others}

Participants deciding for another person may decide more defensively and, in line with the minimax heuristic, focus on avoiding the worst possible outcome, compared with people who decide for themselves. Such a decision behavior has been observed in studies in the medical and the monetary domains: Both actual physicians (Garcia-Retamero \& Galesic, 2012, 2014; Heesen et al., 2017; Ubel, Angott, \& Zikmund-Fisher, 2011) and hypothetical physicians (i.e., participants imagining themselves in the role of physicians; Zikmund-Fisher, Sarr, Fagerlin, \& Ubel, 2006) have been found to make more conservative, less risky choices for their patients compared with when patients choose treatments for themselves. A similar tendency was reported for professional financial planners who made more risk-averse investment choices when dealing with their clients than with their own money (Roszkowski \& Snelbecker, 1990). Findings from L Kray and Gonzalez (1999) and L. J. Kray (2000) also support the assumption that participants deciding for others choose more according to the minimax heuristic than participants deciding for themselves. In their studies, people giving advice took fewer decision attributes into account and decided more heuristically than people deciding for themselves who seemed to decide more in line with trade-off strategies.

\subsubsection{More rational decisions for others}

There is also evidence showing that decisions made for others deviate less from rational choice (i.e., EV maximization) than decisions made for oneself. This has been demonstrated in studies on risk aversion (Sun, Liu, Zhang, \& Lu, 2017; Zhang, Liu, Chen, Shang, \& Liu, 2017), loss aversion (Andersson, Holm, Tyran, \& Wengström, 2013; Mengarelli, Moretti, Faralla, Vindras, \& Sirigu, 2014; Pahlke, Strasser, \& Vieider, 2012; Zhang et al., 2017), and intertemporal choice (Albrecht, Volz, Sutter, Laibson, \& Cramon, 2010). One common explanation for this finding is that decisions for someone else are emotionally less engaging than decisions for oneself, which would allow for a more rational approach to the choice problem (Albrecht et al., 2010; Andersson et al., 2013; Mengarelli et al., 2014; Polman, 2012a; Zhang et al., 2017). In the context of our study, this would predict that people deciding for others will more often decide according to maximizing EV in both domains.

\subsubsection{Decreased monetary-medical gap in choices for others}

Another potential scenario is an interaction between decision perspective and choice domain: If the gap between medical and monetary gambles is indeed due to the medical gambles being more affective ("affect gap"), then this gap may decrease in decisions for others. As stated in the paragraph above, differences between decisions for others and decisions for oneself have been attributed to a decreased emotional engagement when the outcomes affect another person. This assumption of decreased emotional engagement is supported by neuroimaging studies showing a decreased activation of rewardrelated brain areas in choices for others compared with choices for the self (Albrecht et al., 2010; Krigolson, Hassall, Balcom, \& Turk, 2013). Additionally, differences between decisions made for oneself versus others seem to be larger the greater the affective involvement of the participant (Albrecht et al., 2010). Following this line of reasoning, the affective impact of medical side effects may be smaller when people decide for others compared with when they decide for themselves, which, in turn, could make medical decisions for others more similar to monetary decisions. This would decrease the gap between medical and monetary decisions when made for others.

\subsection{Present research}

We conducted two experiments to evaluate these possible scenarios and addressed the following questions: To what extent do medical and monetary decisions for others differ from decisions for oneself in terms of decision strategies and search behavior? Does the gap between medical and monetary decisions persist, or does it decrease? The two experiments cover two important perspectives in decisions for others: In Study 1, participants acted as proxy decision makers and were asked to make (hypothetical) decisions for another student. In Study 2, we asked participants to imagine themselves to be a physician or financial advisor and to give recommendations to a patient or client, respectively.

The paradigm in both experiments was based on Lejarraga et al. (2016), where people made either decisions from description (DfD; i.e., where the characteristics of the gambles' payoff distributions are conveniently summarized) or DfE (i.e., where the characteristics of the gambles' payoff distributions have to be learned from experiential sampling) between several monetary and medical gambles. The amount of search effort in DfE provides insights into how important it is for people to get a precise representation of the outcomes' probabilities.

We expected to replicate previous findings on the monetarymedical gap, namely, that participants choose more often according to the EV strategy and draw larger samples in the monetary domain compared with the medical domain when making decisions for themselves. Regarding the emergence of a gap between medical and monetary choices made for others, the existing literature gives rise to opposing predictions, as described in detail above. If people make more defensive decisions for others, participants in the OTHER 
TABLE 1 Number of participants and descriptive statistics in each of the four experimental conditions

\begin{tabular}{|c|c|c|c|c|c|c|c|c|c|c|c|c|}
\hline \multirow[b]{3}{*}{ Study } & \multicolumn{6}{|c|}{ DfD } & \multicolumn{6}{|c|}{ DfE } \\
\hline & \multicolumn{3}{|c|}{ SELF } & \multicolumn{3}{|c|}{ OTHER } & \multicolumn{3}{|c|}{ SELF } & \multicolumn{3}{|c|}{ OTHER } \\
\hline & $n$ & $\%$ female & $M_{\text {age }}(S D)$ & $n$ & $\%$ female & $M_{\text {age }}(S D)$ & $n$ & $\%$ female & $M_{\text {age }}(S D)$ & $n$ & $\%$ female & $M_{\text {age }}(S D)$ \\
\hline 1 & 40 & 90 & $22.2(4.9)$ & 41 & 88 & $23.0(5.8)$ & 41 & 83 & $20.7(2.1)$ & 40 & 83 & $21.8(4.4)$ \\
\hline 2 & 36 & 86 & $21.8(2.7)$ & 40 & 83 & 22.0 (3.1) & 40 & 83 & $22.8(5.9)$ & 39 & 85 & $22.4(3.8)$ \\
\hline
\end{tabular}

Note. In both studies, participants made the decisions either for themselves (SELF) or for another person (OTHER) and either in a decisions-from-description (DfD) or in a decisions-from-experience (DfE) condition.

condition should choose more often according to the minimax heuristic in both domains than participants in the SELF condition. In Lejarraga et al. (2016), choosing with the goal of avoiding the worst outcome was linked with a reliance on relatively small samples. We therefore expect that choosing according to the minimax heuristic will be associated with lower search effort in the DfE paradigm. If people decide more rationally for others, participants in the OTHER condition should choose more often according to the EV strategy. We again assume that choice is strongly linked to search: People who choose with the goal of maximizing the EV are expected to draw larger samples to get an accurate representation of the true underlying probability. Finally, if the monetary-medical gap is mainly driven by differences in the affective load of the prospects, choice and search behavior in the medical domain should become more similar to the monetary domain in choices for others compared with choices for oneself. This would mean that particularly in the medical domain, choices for others would be more in line with the EV strategy and based on larger samples than choices for oneself.

Because the amount of negative affect related to the outcomes might be an important driver for differences in decision processes between domains and decision perspectives (self vs. other), we additionally elicit participants' affective evaluation of each outcome. On the basis of previous research, we expected that the stronger the affective evaluation of a prospect, the more people neglect probabilities. This would imply fewer choices in line with the EV strategy and smaller samples in affect-rich compared with affect-poor decision problems. ${ }^{1}$

Our two studies allow us to test the robustness of the medicalmonetary discrepancy in decisions for others, and they also contribute to a better understanding of decisions for others more generally. To the best of our knowledge, we are the first to apply formal modeling of decision strategies to self-other decision making. This enables us to get a better understanding of the cognitive processes underlying decisions made for oneself versus for another person. Moreover, it is currently unclear how people sample information in the DfE paradigm when the outcomes do not affect themselves but another person.

\footnotetext{
${ }^{1}$ We refer here to "integral affect" (Lerner, Li, Valdesolo, \& Kassam, 2015) that is directly elicited by the potential outcome of a decision. For a study that investigates the effect of incidental affect on sampling, see Frey, Hertwig, and Rieskamp (2014).
}

\section{METHOD}

To a large extent, the two studies followed the same design. The only difference between the studies refers to the instructions in the OTHER condition, which were framed in terms of a decision for someone else in Study 1 and in terms of a recommendation for someone else in Study 2. We will therefore report methods and results from both studies in parallel.

\section{$2.1 \quad$ Participants}

For Study 1, we recruited 164 participants (139 female; age: $M=21.92$, $S D=4.60$ ). Study 2 included 155 participants (130 female; age: $M=22.25, S D=4.10$ ). Two participants from Study 1 were excluded from the analysis because of unreliable values in the monetary evaluation task (one participant entered the same WTP for every side effect, and another participant reported a WTP of $€ 1,000,000,000$, which was more than 10,000 times the interquartile range of the participant's WTP). In both studies, participants were recruited at the University of Konstanz and received either course credit or $€ 6$ as a compensation for their participation. Overall, the study took around $30 \mathrm{~min}$ to complete.

\subsection{Design}

The experimental design of both studies involved the two betweensubjects factors decision perspective (self vs. other) and decision format (DfD vs. DfE) and the within-subjects factor domain (medical vs. monetary). Participants in both studies were approximately equally distributed across the four different between-subjects conditions (see Table 1).

\subsection{Materials}

In the choice task, participants made 20 binary choices between monetary gambles involving different potential losses and 20 choices between medical gambles, that is, medications that lead to different side effects with a specific probability. We used the same nine choice problems as in Lejarraga et al. (2016) and additionally selected 11 choice problems from Pachur et al. (2014) and Suter et al. (2016). The choice problems were selected such that they included a balanced 
representation of each of the 12 side effects used before and a welldistributed range of probabilities of the side effects from $5 \%$ to $100 \%$. Choice problems with very rare side effects $(<5 \%)$ were not considered as they are very unlikely to be sampled in the DfE paradigm (where people usually do not draw very large samples; e.g., Hertwig et al., 2004). The choice problems of Pachur et al. (2014) and Suter et al. (2016) were constructed such that the EV strategy and the minimax heuristic often make opposing predictions. For participants in our studies, the EV strategy and the minimax heuristic made opposing predictions in, on average, $58 \%$ (Study 1) and $53 \%$ (Study 2) of the choice problems. Only 9\% (Study 1) and 8\% (Study 2) of the choice problems included a dominating option (i.e., an option that is superior in terms of both outcome and probability). A complete list of the choice problems used in both studies can be found in Table A1.

\subsection{Procedure}

\subsubsection{Monetary evaluation task}

At the beginning of the experiment, participants were asked to indicate their WTP to avoid each of the 12 side effects (see Table A2 for median WTPs for each side effect). These monetary evaluations were then used to construct the monetary gambles for each participant. To elicit the WTPs, participants were instructed to imagine that they were suffering from a severe disease and that there existed different medications to treat the disease that were all equally effective but could lead to different side effects. In the SELF condition, participants were then asked how much more they would be willing to pay for a new medication that is as effective as an existing medication but would not have that side effect. They first ranked the side effects by the amount they would be willing to pay to avoid them; in a next step, they then indicated the exact amount of their WTP. In the OTHER condition, participants completed the same task but were asked to estimate the amount that another student would be willing to pay to avoid the side effect. In order to test the reliability of the measure, the monetary evaluation task was presented again at the end of the experiment.

\subsubsection{Choice task}

After the monetary evaluation task, participants were presented with the medical and the monetary choice tasks, with the order of both tasks being counterbalanced across participants. In the medical choice task, participants encountered 20 choice problems in which they had to choose between two different medications. Both medications were described as being equally effective but potentially leading to different side effects with different probabilities. In the monetary choice task, participants were faced with equivalent choice problems, in which the side effects were replaced by their monetary equivalents reported in the monetary evaluation task (their WTP). As in Lejarraga et al. (2016), choices were either presented in a DfD condition or a DfE condition. In the DfD condition, outcomes and their probabilities were fully disclosed to participants (see Figure 1a). In the DfE condition, participants had no prior information about the two options. They could draw a random sample of the binary outcome distribution of each option by pressing a corresponding key on the keyboard. The drawn outcome (either the specific side effect or "No Side Effect" or the specific loss or " $€ 0$ ") would then be presented on the screen under the respective option (see Figure $1 \mathrm{~b}$ ) until the next sample was drawn. Participants could sample from the options in any order and as often as they liked before making a choice.

In the SELF condition, participants made choices as described above; in the OTHER condition, participants were asked to indicate how they would choose for another person. Instructions in the OTHER condition differed between Study 1 and Study 2. In Study 1, participants were told to imagine that a student whom they did not know well but who was also in one of their courses asks them to buy a lottery ticket (monetary domain) or a medication (medical domain) for him or (a)

Potential Side Effect:

Probability:

To choose, press

(b)

To receive more information,
press
$\begin{aligned} & \text { To make you final decision, } \\ & \text { press }\end{aligned}$

Medication A

Memory Loss

$19 \%$

y

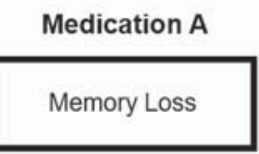

q

y

\section{Medication B}

Fever

$98 \%$

m

Medication B

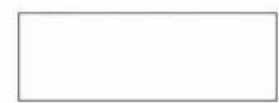

$\mathrm{m}$
FIGURE 1 Screenshot of the choice task in the medical domain (a) in the decisions-fromdescription condition and $(B)$ in the decisionsfrom-experience condition where a participant had clicked on "q" 
her. In Study 2, participants were asked to imagine that they were either a financial advisor (in the monetary domain) or a physician (in the medical domain) and should give a recommendation to a student.

\subsubsection{Affective evaluation task}

To examine the extent to which the side effects and their monetary equivalents triggered different amounts of affect and also whether the decision perspective played a role, participants were asked at the end of the experiment to indicate on a 1-10 scale for each of the medical and monetary outcomes how upset they would feel if they (or the person they made the decision for) actually lost the specific amount or got the specific side effect. ${ }^{2}$

\subsection{Measures}

\subsubsection{Choice behavior: Preference reversals and strategy classification}

To examine the extent to which participants' choices were affected by outcome domain and decision perspective, we first computed how often participants reversed their choices in equivalent choice problems from the medical domain to the monetary domain. Second, we modeled choices with the EV strategy and the minimax heuristic in each condition (similar to Pachur et al., 2014). The EV strategy weights the outcome of an option with its probability (calculates its EV) and chooses the option with the highest EV. The minimax heuristic minimizes the maximal loss and hence chooses the option with the better worst outcome, disregarding the corresponding probabilities. In the medical domain, the WTPs are used to define the values for medical side effects for each participant. To estimate the EV of an option in the DfE condition, we used participants' experienced probabilities, that is, the proportion of times the participant actually encountered the specific outcome. Participants were classified to the strategy with the best fit, using a maximum likelihood approach, similar to Pachur and Galesic (2013), Pachur et al. (2014), and Pachur and Marinello (2013). The goodness of fit of strategy $k$ was determined for each participant as

$$
G_{i, k}^{2}=-2 \sum_{j=1}^{N} \ln \left[f_{j}(y)\right]
$$

where $f_{j}(y)$ represents the probability with which a strategy predicts an individual choice $y$ at choice problem $j$. If Option A was chosen, $f_{j}(y)$ was the probability that the strategy predicted the choice of Option $A$ over Option $B, P_{j}(A, B)$. If Option $B$ was chosen, $f_{j}(y)$ was the probability that the strategy predicted the choice of Option $B, 1-P_{j}(A, B)$. As in Pachur et al. (2014), we defined the probability that the strategy predicted the choice of Option $A\left(P_{j}(A, B)\right)$ with an exponential version of Luce's choice rule (also known as softmax):

$$
P_{j}(A, B)=\frac{e^{\varphi V(A)}}{e^{\varphi V(A)}+e^{\varphi V(B)}}
$$

\footnotetext{
${ }^{2}$ Specifically, we used the German term "verärgert."
}

For the EV strategy, the valuations of Options $A$ and $B$ were defined as $V(A)=x_{A} * p_{A}$ and $V(B)=x_{B} * p_{B}$ ( $x$ is the outcome of the option and $p$ its corresponding probability). For the minimax heuristic, these valuations were defined as $V(A)=x_{A}$ and $V(B)=x_{B}$. The parameter $\varphi$ in Equation (2) represents the sensitivity towards differences in the subjective valuations of the choice problems. It was estimated using a grid search and subsequent optimization with the NelderMead algorithm (using the best solution from the grid search as starting point). If the goodness of fit $G^{2}$ of the best fitting strategy was equal to or bigger than the goodness of fit $G^{2}$ of a random choice $\left(P_{j}(A, B)=0.5\right)$, participants were classified as "guessing or using another strategy" (Pachur et al., 2014).

\subsubsection{Search effort}

Search effort in the DfE condition was measured by the total number of draws (sample size) from both options per choice problem.

\subsection{Analyses}

For all analyses, we applied mixed-effects regression analyses using the Ime4 package in R (Bates, Mächler, Bolker, \& Walker, 2014; R Core Team, 2017). Effects of our factors of interest were examined in a stepwise approach, first estimating the full model and then testing the effect of excluding the relevant factor on model fit using a chi-square test. For readability, the details of the models will be provided below.

\section{RESULTS}

\subsection{Monetary evaluation of side effects}

The WTPs reported in the beginning and at the end of the experiment were highly correlated (mean correlation across participants: Study 1: $r=0.975$; Study 2: $r=0.959$ ), indicating that they are a reliable measure over time. Figure 2 displays the reported WTPs to avoid each of the 12 side effects (monetary equivalents) across participants in both conditions (SELF and OTHER). The amounts that participants reported ranged from 0 up to $€ 1,000,000$ (Study $1: M d n=€ 40, M=€ 1,887$; Study 2: $M d n=€ 30, M=€ 3,782)$. In the OTHER condition, participants were asked to report how much they thought the other student would be willing to pay to avoid each of the side effects. Although WTPs in the OTHER condition seemed to be generally lower than in the SELF condition, excluding the dummy coding of decision perspective from the model did not lead to a significantly poorer model fit, Study 1: $\chi^{2}(1)=2.31, p=0.128$; Study $2: \chi^{2}(1)=1.81, p=0.179$. As the values of the WTP variable were highly right-skewed, we reran the model using log-transformed WTPs. In this analysis, decision perspective predicted the (log-transformed) WTP, Study 1: $\chi^{2}(1)=6.29$, $p=0.012$; Study 2: $\chi^{2}(1)=5.90, p=0.015$, with WTPs being higher in the SELF condition than in the OTHER condition. 


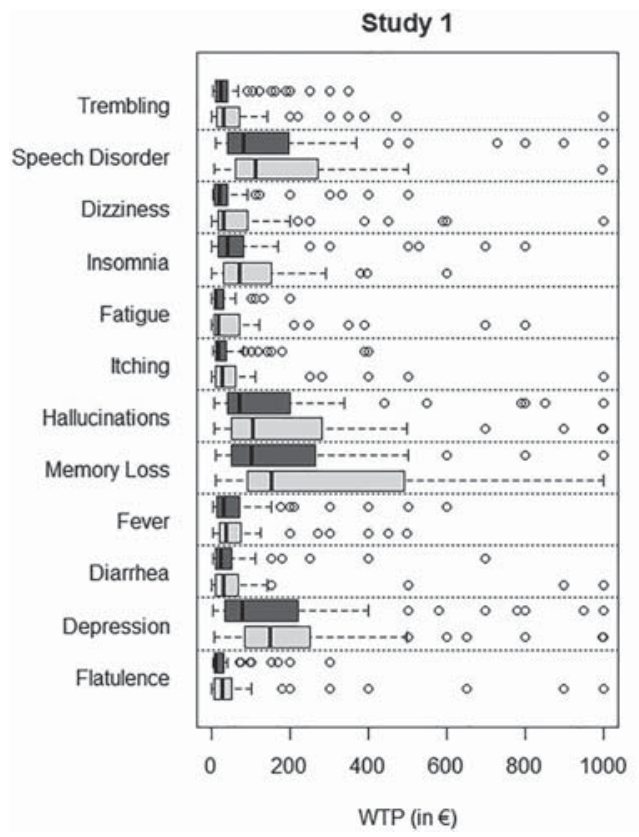

WTP (in $€$ )
Study 2

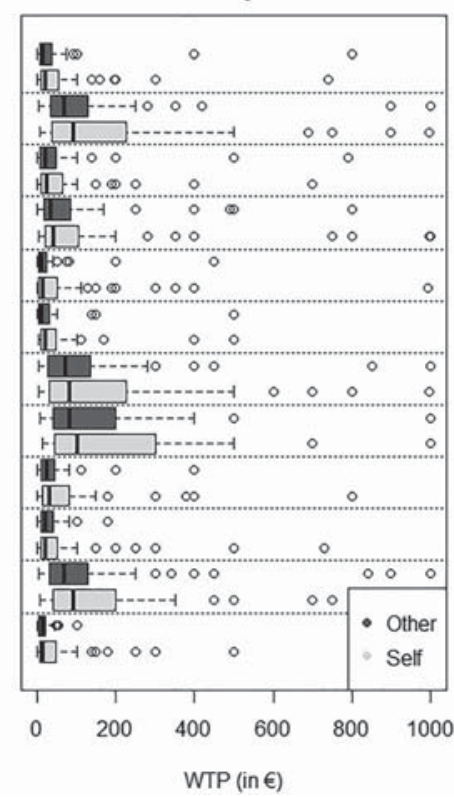

FIGURE 2 Reported willingness to pay (WTP; in $€$ ) to avoid the specific side effect. In the OTHER condition, participants were asked to report how much they think the other student would be willing to pay to avoid the specific side effect. The right and left limits of the boxes denote the first and third quartiles. The whiskers denote the lowest datum within 1.5 interquartile range (IQR) of the first quartile and the highest datum within 1.5 IQR of the third quartile. Not shown are values above a WTP of $€ 1,000$ (but they are included in the boxplots)

\subsection{Choice behavior}

\subsubsection{Choice reversals}

Did people choose differently in the medical than in the monetary choice task? As in Pachur et al. (2014), participants reversed their choices between the medical and the corresponding monetary choice problems in about $40 \%$ of the cases (with $M=40 \%$ and $M=44 \%$ in Studies 1 and 2, respectively). In both studies, a mixed-effects logistic regression analysis, with participants and choice problem as random effects and decision perspective (SELF vs. OTHER) and decision format (DfD vs. DfE) as fixed effects, did not show a difference between the SELF and OTHER conditions, Study 1: $\chi^{2}(1)=0.72, p=0.396$; Study 2: $\chi^{2}(1)=1.14, p=0.285$. Preference reversals, however, occurred somewhat more often in the DfD condition than in the DfE condition in Study $2, \chi^{2}(1)=7.79, p=0.005$, but less so in Study $1, \chi^{2}(1)=2.35, p=0.125$ (percentage of choice reversals: Study 1 DfD: 42\%, Study 1 DfE: 38\%; Study 2 DfD: 47\%, Study 2 DfE: 40\%).

\subsubsection{Strategy classification}

Results of the strategy classification are summarized in Figure 3. Consistently, over the four conditions of our two studies, participants were more often classified as following the EV strategy in the monetary domain than in the medical domain and following the minimax heuristic more often in the medical domain than in the monetary domain. To test the effect of domain, decision format and decision perspective on strategy use, we created a dummy variable for whether participants were classified as following the EV strategy or not and ran a mixed logistic regression analysis with the above-mentioned variables as fixed effects and participants as random effect. Additionally, we tested whether adding interaction terms would improve model fit. In both studies, more participants were classified as following the EV strategy in the monetary domain than in the medical domain, Study $1: \chi^{2}(1)=86.9$, $p<0.001$; Study $2: \chi^{2}(1)=95.2, p<0.001$, but there was no main effect of the decision perspective, Study $1: \chi^{2}(1)=1.09, p=0.296$; Study 2 : $\chi^{2}(1)=1.13, p=0.288$. However, there was an interaction between domain and decision perspective in Study $2, \chi^{2}(1)=4.59, p=0.032$, with fewer participants being classified as following the EV strategy in the monetary domain and the OTHER condition than in the SELF condition. Furthermore, there was an effect of decision format in Study 2 with more participants classified as following the EV strategy and fewer as following the minimax heuristic in the DfD condition compared with the DfE condition (EV strategy: DfD: 61.36\%, DfE: 48.73\%; minimax: DfD: $33.77 \%$, DfE: $37.34 \%$ ). This is consistent with results in Lejarraga et al. (2016), where minimax predicted slightly more choices in the DfE condition than in the DfD condition.

\subsection{Search effort}

In the DfE condition, participants drew a relatively large number of samples, with an average number of draws per choice problem of $M=33.2(S D=35.1 ; M d=26)$ and $M=30.1(S D=21.7 ; M d=26)$ in Studies 1 and 2, respectively. ${ }^{3}$ To predict the effect of choice domain and decision perspective on sample size, we ran a mixed-effects linear

\footnotetext{
${ }^{3}$ These numbers are relatively large compared with a mean of 19.4 draws in Lejarraga et al. (2016) and a median of 22 for choices with two risky options reported in a meta-analytic review by Wulff, Mergenthaler-Canseco, and Hertwig (2018). One reason for this relatively high number of draws might be that sampling in our experimental paradigm was made very easy: In order to sample from an option, participants did not first have to select an option with the mouse, but they just had to press a certain key on the keyboard. The feedback would then directly appear on the screen. Moreover, our choice problems involved only negative outcomes that also have been found to increase search effort (Lejarraga, Hertwig, \& Gonzalez, 2012; Wulff et al., 2018).
} 

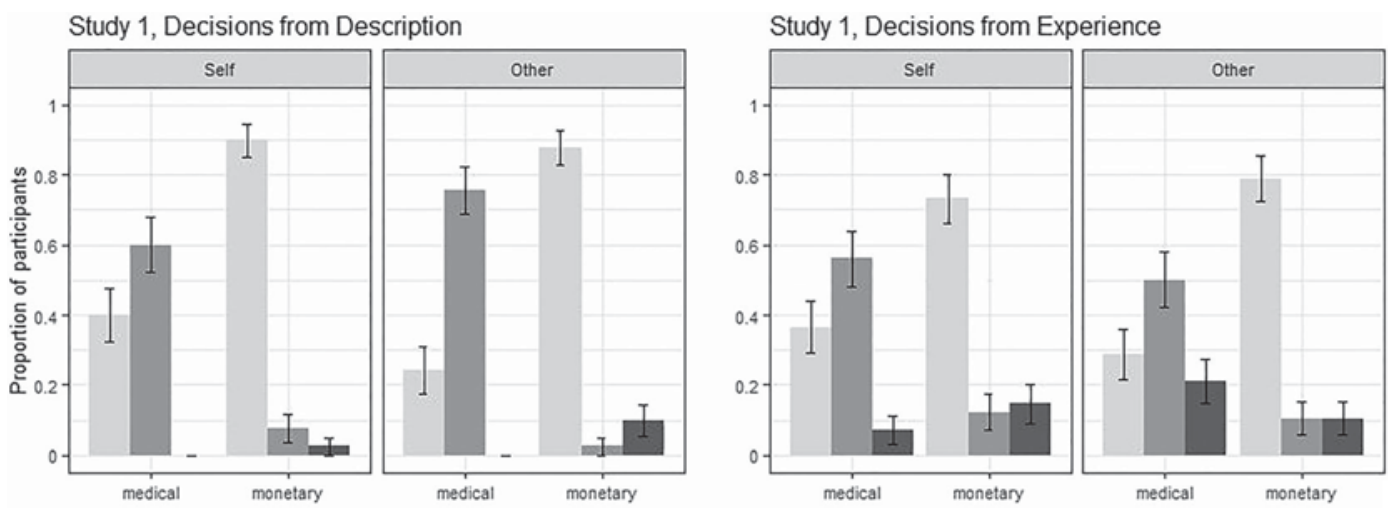

Study 2, Decisions from Description

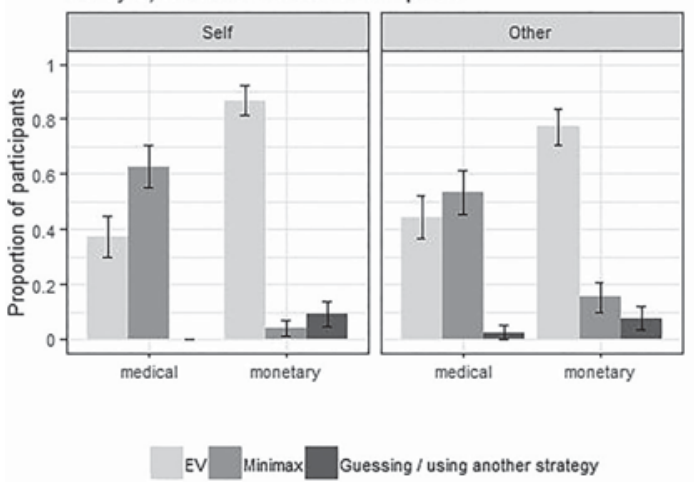

Study 2, Decisions from Experience

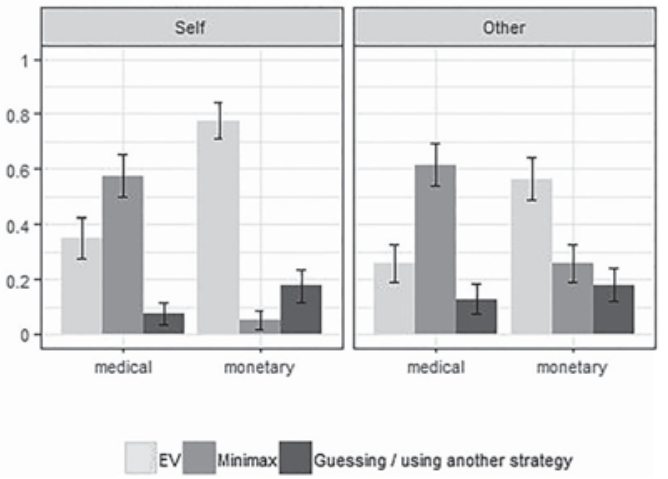

FIGURE 3 Proportion of participants classified as following the expected value (EV) strategy and the minimax heuristic and as guessing/using another strategy in the four conditions of our two studies, respectively. Error bars denote \pm standard errors of the proportion

regression, additionally controlling for the difficulty of the choice problem, EVdiff (measured as relative difference of the EVs of both options). Domain, decision perspective, and EVdiff were treated as fixed effects and participant and choice problem as random effects. Moreover, we added individual-specific random slopes for domain and an interaction between domain and decision perspective. The number of draws per choice problem was lower in the medical domain than in the monetary domain in both studies, Study $1: \chi^{2}(1)=12.5$, $p<0.001$; Study 2: $\chi^{2}(1)=8.73, p=0.003 .{ }^{4}$ As can be seen in Figure 4 , this difference held regardless of whether participants were making decisions for themselves or for another student. Although participants took slightly smaller samples in both domains across both studies in the OTHER condition compared with the SELF condition (see Figure 4), decision perspective did not predict sample size, Study 1: $\chi^{2}(1)=0.36, p=0.546$; Study $2: \chi^{2}(1)=0.25, p=0.616$. There was also no interaction between decision perspective and domain, Study 1 : $\chi^{2}(1)=1.63, p=0.201 ;$ Study $1: \chi^{2}(1)=0.56, p=0.455$; Study 2 : $\chi^{2}(1)=0.00, p=0.969$. These findings are in line with the results on participants' choice behavior, where those deciding for/giving a recommendation to another student followed similar decision strategies

${ }^{4}$ This effect was disturbed by an outlier in Study 1 who drew substantially more samples in the OTHER condition than the other participants $(M=167.6$, maximum $=399, S D=101$; see Figure $A 2$ ). We excluded this outlier from the analyses reported here. Results on search effort including the outlier are shown in Figure A1. in both domains as participants deciding for themselves. Indeed, choice behavior was linked to sample size: Participants classified as following the EV strategy sampled on average more than those classified as following the minimax heuristic-Study 1: sample size EV strategy: 34.96 , sample size minimax heuristic: $27.95, t(114.7)=2.42$, $p=0.017$; Study 2: sample size EV strategy: 34.70 , sample size minimax heuristic: $26.48, t(125.03)=3.26, p=0.001$. Participants who were classified as guessing or following another strategy drew the smallest samples overall (Study 1: 13.55; Study 2: 23.92).

\subsection{Affective evaluation}

The average affective ratings for each side effect and its monetary equivalent in the SELF and OTHER conditions are displayed in Figure 5. In the OTHER condition, participants were asked to report how upset they would feel if the person they made the decision/ recommendation for actually lost the specific amount or got the specific side effect. Affective ratings were higher for medical side effects than for monetary losses-mixed-effects linear regression with participants as random effects and side effects, domain, decision perspective, and decision format as fixed effects: Study $1: \chi^{2}(1)=30.8$, $p<0.001$; Study $2: \chi^{2}(1)=192.7, p<0.001-$ this is consistent with previous studies on discrepancies in medical and monetary decisions (Pachur et al., 2014; Pachur \& Galesic, 2013). There was no effect of 
Study 1

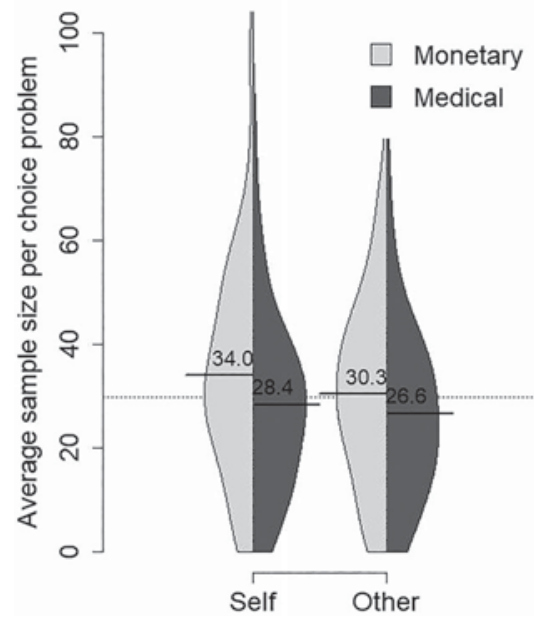

Study 1

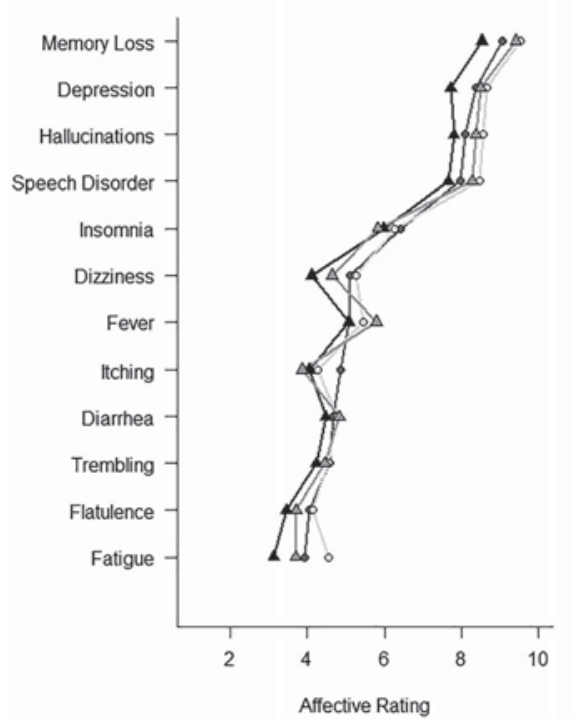

Study 2

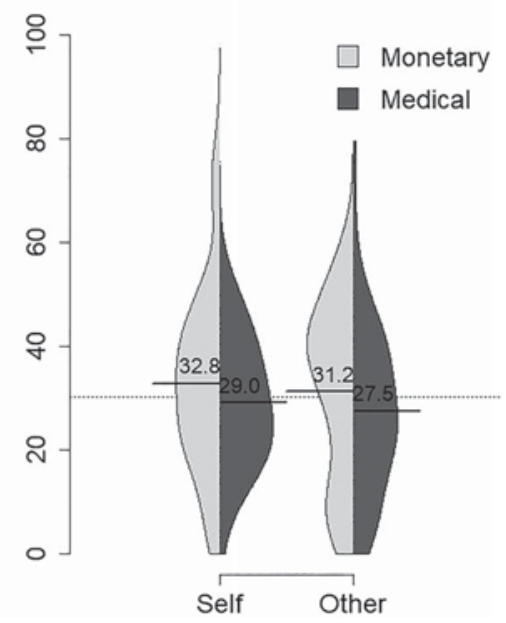

Study 2

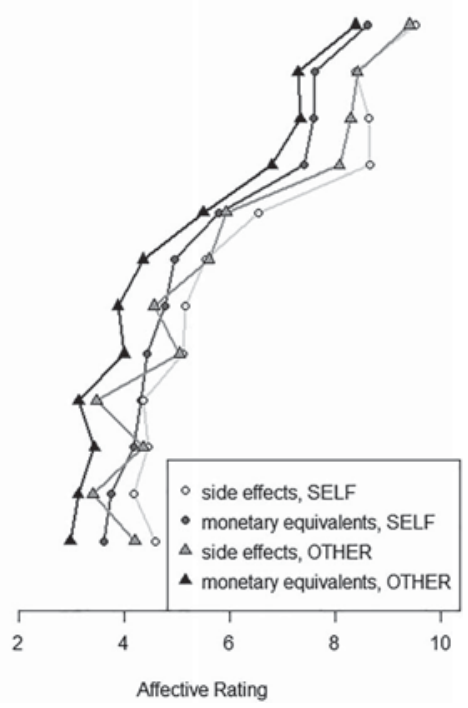

FIGURE 4 Average sample size per choice problem in the decisions-from-experience condition. Whereas sample size was larger in the monetary than in the medical domain, decision perspective (self vs. other) did not influence sample size
FIGURE 5 Mean affective ratings (ranging from 0 to 10) for side effects and their monetary equivalents (willingness to pay) in the SELF and OTHER conditions of both studies decision format on affective rating, Study $1: \chi^{2}(1)=0.13, p=0.716$; Study $2: \chi^{2}(1)=0.05, p=0.821$, but of decision perspective: Participants reported to feel less upset when somebody else would experience the outcome as when they themselves would experience it, Study 1: $\chi^{2}(1)=4.42, p<0.036$; Study $2: \chi^{2}(1)=8.14, p<0.004$. However, as reported above, participants indicated lower WTPs when asked to estimate what the other person would pay to avoid the specific side effect than when reporting the WTPs for themselves. They were therefore also presented with, on average, lower monetary values in the affective evaluation task than participants in the SELF condition. These lower values might have driven the effect of the OTHER condition on affective rating. To control for this difference in monetary amounts, we conducted a mixed-effects regression analysis separately for the medical and the monetary domains, using the type of side effect in the medical domain and the amount of WTP in the monetary domain as covariates. This analysis showed that only for medical side effects in Study 2, decision perspective remained a significant predictor of affective rating, $\chi^{2}(1)=5.24, p=0.022$. The lower affective rating in the OTHER condition can, hence, partly be explained by the lower estimated valuation of the side effects by others in terms of WTP.

\section{DISCUSSION}

Results from our two studies demonstrate that the gap between medical and monetary decisions is a robust phenomenon that persists when decision outcomes affect another person rather than oneself. Participants who were asked to make choices or give recommendations for somebody else systematically reversed their choices between monetary and medical gambles just as often as participants making choices for themselves. Formal modeling revealed that choices for others could be described in a very similar way as choices for oneself: In both conditions, monetary choices were better modeled with the compensatory EV strategy, which weights outcomes with their corresponding probabilities, than with the minimax heuristic. Medical choices were better described by the minimax heuristic, which neglects probabilities and minimizes the worst possible outcome. These patterns in choice were 
also reflected in participants' search effort in the DfE paradigm: When making medical choices for oneself and for others, participants relied on much smaller samples than when making monetary choices.

\subsection{Implications for the gap between medical and monetary decisions}

Our results closely replicate Lejarraga et al. (2016) and Pachur et al. (2014) and support their finding that choice and search behavior differ between decisions involving medical and monetary prospects. Specifically, probability information tends to be neglected in medical decisions. Such a replication of previous findings is especially valuable in light of the recent replication crisis in the social sciences (Camerer et al., 2018; Open Science Collaboration, 2015). As a novel contribution, our results showed that the gap between medical and monetary decisions generalizes to choices for others: Choice behavior and information search in medical decisions differ from monetary decisions irrespective of who is affected by the outcome.

This difference between medical and monetary decisions has various important implications: First, it demonstrates that decision behavior is highly context dependent and more influenced by the type of prospect (in our case monetary losses vs. medical side effects) than by who is affected by these prospects. Caution is thus warranted when generalizing findings from experiments on risky choices involving monetary outcomes to other decision contexts. Second, demonstrating that people seem to disregard probabilities in medical decisions, and that this also holds true for decisions and recommendations for others, implies a challenge for informed medical decision making. To overcome this challenge, effective risk communication tools that help patients as well as doctors to adequately take into account probability information have been developed. Such tools include, for example, well-designed visual aids such as icon arrays or bar graphs that have been found to significantly improve comprehension of risk information (Garcia-Retamero \& Cokely, 2013).

Zhang et al. (2017) argued that physicians may make better medical decisions if they make it for a socially distant person rather than a friend or themselves. Our findings suggest that even when the patient is a stranger, this may not be the case. However, whether these findings from hypothetical laboratory medical decisions also generalize to decisions of actual physicians remains to be investigated by future research.

\subsection{Implications for self-other decision making}

In both studies, choice behavior, decision strategies, and sampling behavior of participants deciding for others were very similar to participants deciding for themselves. The only difference we found occurred in the monetary domain of Study 2, where decisions for oneself were in accordance with the EV strategy more often than recommendations for others whereas recommendations for others were slightly more defensive and less in accordance with the EV strategy than decisions for oneself. Note, however, that this effect was small and the overall pattern of strategy classifications was, by and large, comparable between decision perspectives.

In contrast to our findings, most published studies on self-other decision making have found differences between the two decision perspectives. There are various reasons that could explain this discrepancy: First, due to publication bias, studies with statistically nonsignificant results may have been less likely to be published than studies that report significant results (loannidis, Munafò, Fusar-Poli, Nosek, \& David, 2014; Sterling, 1959). Second, the type of decision task in our study was different from most of the previous studies on decisions for others (lottery choices purely in the loss domain and with only one aversive outcome per option). To the best of our knowledge, we are the first to examine the decision strategies people use in choices between gambles made for others. Studies on similar tasks, however, also found similar results. One yet unpublished study on DfE for others also found no difference in search effort between situations when outcomes affected participants themselves or another participant (Olschewski, Dietsch, \& Ludvig, 2017). Sun et al. (2017) investigated choices for self and other in daily-life decision scenarios involving either monetary gains or losses and found differences in risky choices for self versus others only in the gain domain but not in the loss domain. They explain this finding by an asymmetry in empathizing with others' positive and negative experiences: Empathizing with others' losses seems to be easier than empathizing with other's gains. The gambles in our studies included only negative outcomes. To better understand decisions for others, future research should systematically vary not only the type of decision (e.g., proxy decision making vs. providing a recommendation) and social distance to the other person but also the value of the decision outcome, and whether it is a gain or loss, as well as the accountability or need for justification of the decision maker.

One limitation of our study is that we asked participants to decide for an abstract "other student." Such a decision might be quite different from real-world decisions for others, where one usually knows the other person and her preferences. Instructions to imagine an abstract other are quite common in research on decisions for others (L. Kray \& Gonzalez, 1999; Polman, 2010, 2012b; Sun et al., 2017). However, this approach can produce quite some heterogeneity in who people imagine, from a close friend to a complete stranger. We aimed to reduce this heterogeneity by asking participants to imagine another student whom they do not know well but who is in one of their courses. They, hence, were all supposed to imagine a socially distant other from the same peer group. A next step would be to study monetary and medical decisions for others with actual dyads.

\subsection{The role of affect}

Similar to previous studies on the gap between medical and monetary decisions, participants in our study indicated, on average, that they would feel more upset when experiencing a medical side effect than when experiencing the monetarily equivalent loss. This gap in affective valuation was also found when participants evaluated outcomes that would be experienced by the person they made the decision for. Overall, participants in the OTHER condition of both studies reported lower 
affect than participants in the SELF condition. Participants deciding for others were therefore presented with gambles whose outcomes were associated with lower levels of negative affect than participants deciding for themselves. This difference in affective value of the outcomes, however, did not translate into differences in choice and search behavior, suggesting that affect might not be the main driver of the discrepancy between medical and monetary decisions. In additional analyses reported in Appendix A, we tested whether search effort differed between affect-rich and affect-poor gambles of the same domain and found no such difference.

Another factor that is likely to have fueled differences in decision processes between the two domains is the evaluability of the outcomes: Monetary losses have a clearly defined, numerical value that can easily be weighted with probabilities. Medical side effects, by contrast, do not have such a clearly defined value in form of a number. Their evaluation is probably more based on a feeling that may be more difficult to weight by a numerical probability. Medical gains and losses also do not directly compensate each other in contrast to monetary outcomes. For example, treating an abnormal heart rhythm does not make up for a broken arm. This holds true regardless of whether the outcome affects oneself or another person.

\subsection{Predicted WTP}

To obtain monetary equivalents for the medical side effects, we asked participants how much they would be willing to pay to avoid the specific side effect. In the OTHER condition, participants reported the amount they predicted another person to be willing to pay to avoid the side effect. In both studies, this predicted WTP was, on average, lower than the WTP participants reported for themselves. In a number of studies, Frederick (2012) found higher predicted WTP of others. However, this was only the case when people were asked about the WTP to experience positive events. When asked about a compensation for experiencing a negative event (such as shaving the head), which is very similar to asking for the WTP to avoid a negative event, people predicted that others would demand a smaller amount than themselves. Similarly, Hsee and Weber (1997) showed that people predicted others to be more willing to take risks than themselves. As explanation for these findings, the authors of both studies suggested that people might have difficulties empathizing with the feelings of socially distant others and tend to underestimate how others evaluate negative events. Our finding that people provided lower WTPs and lower affective ratings in the OTHER condition than in the SELF condition is consistent with this notion.

\section{CONCLUSION}

In two studies, we extended findings on the gap between medical and monetary decisions under risk to decisions made for others. In decisions with monetary prospects, people generally trade off outcomes with their probabilities. In decisions with medical prospects, people tend to rely more on a heuristic strategy that focuses on the outcome of the decision while ignoring its respective probability. Our results indicate that the gap between medical and monetary decisions persists when decision makers are not affected by the outcome themselves but rather make a decision or recommendation for another person. Formal modeling of decision strategies and an analysis of sampling behavior in the DfE paradigm indicated that risky choices made for others and made for oneself are based on similar processes. These findings suggest that decisions under risk and their underlying processes are more influenced by the type of prospect of the decision, such as monetary losses versus medical side effects, than by who is affected by this prospect.

\section{ACKNOWLEDGEMENTS}

This research was supported by the German Research Foundation (DFG, FOR 2374) and the Graduate School of Decision Sciences (also funded by the DFG). We thank Lisann Appelius, Florian Ermark, Nico Gradwohl, Leonie Mack, Lea Riegler, and Helen Schiek for their help in conducting the experiments.

\section{ORCID}

Nathalie F. Popovic (1) https://orcid.org/0000-0001-8297-341X

\section{REFERENCES}

Albrecht, K., Volz, K. G., Sutter, M., Laibson, D. I., \& Cramon, D. Y. v. (2010). What is for me is not for you: Brain correlates of intertemporal choice for self and other. Social Cognitive and Affective Neuroscience, 6(2), 218-225. https://doi.org/10.1093/scan/nsq046

Andersson, O., Holm, H. J., Tyran, J.-R., \& Wengström, E. (2013). Deciding for others reduces loss aversion (No. 976). IFN Working Paper. Retrieved from http://www.econstor.eu/handle/10419/95623

Bates, D., Mächler, M., Bolker, B., \& Walker, S. (2014). Fitting linear mixedeffects models using Ime4. Journal of Statistical Software, 67(1), 1-48. Retrieved from http://arxiv.org/abs/1406.5823

Bernoulli, D. (1954). Exposition of a new theory on the measurement of risk. Econometrica, 22(1), 23-36.

Camerer, C. F., Dreber, A., Holzmeister, F., Ho, T.-H., Huber, J., Johannesson, M., ... Wu, H. (2018). Evaluating the replicability of social science experiments in Nature and Science between 2010 and 2015. Nature Human Behaviour, 2(9), 637-644. https://doi.org/10.1038/s41562-018-0399-z

Core Team, R. (2017). R: A language and environment for statistical computing. Vienna, Austria: R Foundation for Statistical Computing. Retrieved from https://www.R-project.org/

Frederick, S. (2012). Overestimating others' willingness to pay. Journal of Consumer Research, 39(1), 1-21. https://doi.org/10.1086/662060

Frey, R., Hertwig, R., \& Rieskamp, J. (2014). Fear shapes information acquisition in decisions from experience. Cognition, 132(1), 90-99. https:// doi.org/10.1016/j.cognition.2014.03.009

Garcia-Retamero, R., \& Cokely, E. T. (2013). Communicating health risks with visual aids. Current Directions in Psychological Science, 22(5), 392-399. https://doi.org/10.1177/0963721413491570

Garcia-Retamero, R., \& Galesic, M. (2012). Doc, what would you do if you were me? On self-other discrepancies in medical decision making. Journal of Experimental Psychology: Applied, 18(1), 38-51. https://doi. org/10.1037/a0026018

Garcia-Retamero, R., \& Galesic, M. (2014). On defensive decision making: How doctors make decisions for their patients. Health Expectations, 17(5), 664-669. https://doi.org/10.1111/j.1369-7625.2012.00791.x 
Gurmankin, A. D., Baron, J., Hershey, J. C., \& Ubel, P. A. (2002). The role of physicians' recommendations in medical treatment decisions. Medical Decision Making: An International Journal of the Society for Medical Decision Making, 22(3), 262-271. https://doi.org/10.1177/0272989X0202200314

Heesen, C., Kleiter, I., Meuth, S. G., Krämer, J., Kasper, J., Köpke, S., \& Gaissmaier, W. (2017). Benefit-risk perception of natalizumab therapy in neurologists and a large cohort of multiple sclerosis patients. Journal of the Neurological Sciences, 376, 181-190. https://doi.org/10.1016/j.jns.2017.03.001

Hertwig, R., Barron, G., Weber, E. U., \& Erev, I. (2004). Decisions from Experience and the Effect of Rare Events in Risky Choice. Psychological Science, 15(8), 534-539.

Hsee, C. K., \& Weber, E. U. (1997). A fundamental prediction error: Self-others discrepancies in risk preference. Journal of Experimental Psychology: General, 126(1), 45-53. https://doi.org/10.1037/0096-3445.126.1.45

Ioannidis, J. P. A., Munafò, M. R., Fusar-Poli, P., Nosek, B. A., \& David, S. P. (2014). Publication and other reporting biases in cognitive sciences: Detection, prevalence, and prevention. Trends in Cognitive Sciences, 18(5), 235-241. https://doi.org/10.1016/j.tics.2014.02.010

Kellen, D., Pachur, T., \& Hertwig, R. (2016). How (in)variant are subjective representations of described and experienced risk and rewards? Cognition, 157, 126-138.

Kray, L., \& Gonzalez, R. (1999). Differential weighting in choice versus advice: I'll do this, you do that. Journal of Behavioral Decision Making, 12(3), 207-218. https://doi.org/10.1002/(SICI)1099-0771(199909) 12:3<207::AID-BDM322>3.0.CO;2-P

Kray, L. J. (2000). Contingent weighting in self-other decision making. Organizational Behavior and Human Decision Processes, 83(1), 82-106. https://doi.org/10.1006/obhd.2000.2903

Krigolson, O. E., Hassall, C. D., Balcom, L., \& Turk, D. (2013). Perceived ownership impacts reward evaluation within medial-frontal cortex. Cognitive, Affective \& Behavioral Neuroscience, 13(2), 262-269. https://doi.org/10.3758/s13415-012-0144-4

Lejarraga, T., Hertwig, R., \& Gonzalez, C. (2012). How choice ecology influences search in decisions from experience. Cognition, 124(3), 334-342. https://doi.org/10.1016/j.cognition.2012.06.002

Lejarraga, T., Pachur, T., Frey, R., \& Hertwig, R. (2016). Decisions from experience: From monetary to medical gambles. Journal of Behavioral Decision Making, 29(1), 67-77. https://doi.org/10.1002/bdm.1877

Lerner, J. S., Li, Y., Valdesolo, P., \& Kassam, K. S. (2015). Emotion and decision making. Annual Review of Psychology, 66, 799-823. https://doi. org/10.1146/annurev-psych-010213-115043

Mengarelli, F., Moretti, L., Faralla, V., Vindras, P., \& Sirigu, A. (2014). Economic decisions for others: An exception to loss aversion law. PLOS ONE, 9(1), e85042. https://doi.org/10.1371/journal.pone.0085042

Olschewski, S., Dietsch, M., \& Ludvig, E. (2017). Competitive motives explain risk aversion for others in decisions from experience. PsyArXiv. https://doi.org/10.17605/OSF.IO/A7WE3

Open Science Collaboration (2015). Estimating the reproducibility of psychological science. Science, 349(6251), aac4716. https://doi.org/ 10.1126/science.aac4716

Pachur, T., \& Galesic, M. (2013). Strategy selection in risky choice: The impact of numeracy, affect, and cross-cultural differences. Journal of Behavioral Decision Making, 26(3), 260-271. https://doi.org/10.1002/bdm.1757

Pachur, T., Hertwig, R., \& Wolkewitz, R. (2014). The affect gap in risky choice: Affect-rich outcomes attenuate attention to probability information. Decision, 1(1), 64-78. https://doi.org/10.1037/dec0000006

Pachur, T., \& Marinello, G. (2013). Expert intuitions: How to model the decision strategies of airport customs officers? Acta Psychologica, 144(1), 97-103. https://doi.org/10.1016/j.actpsy.2013.05.003
Pahlke, J., Strasser, S., \& Vieider, F. M. (2012). Risk-taking for others under accountability. Economics Letters, 114(1), 102-105. https://doi.org/ 10.1016/j.econlet.2011.09.037

Petrova, D. G., van der Pligt, J., \& Garcia-Retamero, R. (2014). Feeling the numbers: On the interplay between risk, affect, and numeracy. Journal of Behavioral Decision Making, 27(3), 191-199. https://doi.org/ 10.1002/bdm.1803

Polman, E. (2010). Information distortion in self-other decision making. Journal of Experimental Social Psychology, 46(2), 432-435. https://doi. org/10.1016/j.jesp.2009.11.003

Polman, E. (2012a). Effects of self-other decision making on regulatory focus and choice overload. Journal of Personality and Social Psychology, 102(5), 980-993. https://doi.org/10.1037/a0026966

Polman, E. (2012b). Self-other decision making and loss aversion. Organizational Behavior and Human Decision Processes, 119(2), 141-150. https://doi.org/10.1016/j.obhdp.2012.06.005

Roszkowski, M. J., \& Snelbecker, G. E. (1990). Effects of "framing" on measures of risk tolerance: Financial planners are not immune. Journal of Behavioral Economics, 19(3), 237-246. https://doi.org/10.1016/00905720(90)90029-7

Rottenstreich, Y., \& Hsee, C. K. (2001). Money, kisses, and electric shocks: On the affective psychology of risk. Psychological Science, 12(3), 185-190. https://doi.org/10.1111/1467-9280.00334

Savage, L. J. (1951). The theory of statistical decision. Journal of the American Statistical Association, 46(253), 55-67. https://doi.org/10.1080/ 01621459.1951.10500768

Sterling, T. D. (1959). Publication decisions and their possible effects on inferences drawn from tests of significance-Or vice versa. Journal of the American Statistical Association, 54(285), 30-34. https://doi.org/ 10.1080/01621459.1959.10501497

Sun, Q., Liu, Y., Zhang, H., \& Lu, J. (2017). Increased social distance makes people more risk-neutral. The Journal of Social Psychology, 157(4), 502-512. https://doi.org/10.1080/00224545.2016.1242471

Sunstein, C. R. (2003). Terrorism and probability neglect. Journal of Risk and Uncertainty, 26(2-3), 121-136. https://doi.org/10.1023/A:10241 11006336

Suter, R. S., Pachur, T., \& Hertwig, R. (2016). How affect shapes risky choice: Distorted probability weighting versus probability neglect. Journal of Behavioral Decision Making, 29(4), 437-449. https://doi.org/10.1002/ bdm.1888

Suter, R. S., Pachur, T., Hertwig, R., Endestad, T., \& Biele, G. (2015). The neural basis of risky choice with affective outcomes. PLOS ONE, 10(4). https://doi.org/10.1371/journal.pone.0122475), e0122475.

Ubel, P. A., Angott, A. M., \& Zikmund-Fisher, B. J. (2011). Physicians recommend different treatments for patients than they would choose for themselves. Archives of Internal Medicine, 171(7), 630-634. https:// doi.org/10.1001/archinternmed.2011.91

Wulff, D. U., Mergenthaler-Canseco, M., \& Hertwig, R. (2018). A metaanalytic review of two modes of learning and the descriptionexperience gap. Psychological Bulletin, 144, 140-176. https://doi.org/ 10.1037/bul0000115

Zhang, X., Liu, Y., Chen, X., Shang, X., \& Liu, Y. (2017). Decisions for others are less risk-averse in the gain frame and less risk-seeking in the loss frame than decisions for the self. Frontiers in Psychology, 8, 1601. https://doi.org/10.3389/fpsyg.2017.01601

Zikmund-Fisher, B. J., Sarr, B., Fagerlin, A., \& Ubel, P. A. (2006). A matter of perspective: Choosing for others differs from choosing for yourself in making treatment decisions. Journal of General Internal Medicine, 21(6), 618-622. https://doi.org/10.1111/j.1525-1497.2006.00410.x 


\section{AUTHOR BIOGRAPHIES}

Nathalie F. Popovic is a PhD candidate at the Graduate School of Decision Sciences and Associated Fellow at the Zukunftskolleg, both at the University of Konstanz, Germany. She investigates how people make judgments and decisions in a social context and under stress.

Thorsten Pachur is Senior Research Scientist at the Center for Adaptive Rationality at the Max Planck Institute for Human Development in Berlin. He studies learning and memory processes in decision making, strategy selection, and the psychology of risky choice, using computational modeling and process analyses.
Wolfgang Gaissmaier, PhD, has been a Full Professor of Social Psychology and Decision Sciences at the University of Konstanz, Germany, since 2014. His research investigates how people make decisions under uncertainty and how risks can be communicated more successfully to help people make better decisions, particularly about health.

\section{APPENDIX A}

\section{A.1 Choice problems}

TABLE A1 Medical choice problems

\begin{tabular}{|c|c|c|c|c|}
\hline & \multicolumn{2}{|l|}{ Option A } & \multicolumn{2}{|l|}{ Option B } \\
\hline & Side effect & Probability & Side effect & Probability \\
\hline 1 & Flatulence & 1.00 & Hallucinations & 0.25 \\
\hline 2 & Fatigue & 0.90 & Memory loss & 0.25 \\
\hline 3 & Itching & 0.70 & Depression & 0.25 \\
\hline 4 & Fever & 0.40 & Hallucinations & 0.20 \\
\hline 6 & Speech disorder & 0.30 & Memory loss & 0.20 \\
\hline 7 & Fatigue & 0.70 & Dizziness & 0.30 \\
\hline 8 & Itching & 0.60 & Trembling & 0.50 \\
\hline 9 & Flatulence & 0.70 & Diarrhea & 0.40 \\
\hline 10 & Depression & 0.50 & Memory loss & 0.10 \\
\hline 11 & Memory loss & 0.10 & Insomnia & 0.20 \\
\hline 13 & Hallucinations & 0.30 & Diarrhea & 0.98 \\
\hline 14 & Fatigue & 0.99 & Insomnia & 0.70 \\
\hline 15 & Speech disorder & 0.05 & Trembling & 0.94 \\
\hline 16 & Itching & 0.54 & Depression & 0.05 \\
\hline 17 & Memory loss & 0.19 & Fever & 0.98 \\
\hline 18 & Itching & 0.60 & Trembling & 0.50 \\
\hline 19 & Speech disorder & 0.56 & Insomnia & 0.98 \\
\hline 20 & Dizziness & 0.98 & Memory loss & 0.55 \\
\hline
\end{tabular}

Note. In the monetary domain, side effects were replaced by each participant's monetary evaluation of the specific side effect. 
A.2 Monetary evaluations of side effects and affective evaluations of side effects and their monetary equivalents

TABLE A2 Median monetary equivalents of side effects and mean affective ratings of the side effects and their monetary equivalents

\begin{tabular}{|c|c|c|c|c|c|c|}
\hline \multirow[b]{3}{*}{ Side effect } & \multirow{2}{*}{\multicolumn{2}{|c|}{$\begin{array}{l}\text { Monetary equivalent in } € \\
\text { Md }\end{array}$}} & \multicolumn{4}{|c|}{ Affective rating } \\
\hline & & & \multicolumn{2}{|c|}{$\begin{array}{l}\text { Side effect } \\
M\end{array}$} & \multicolumn{2}{|c|}{$\begin{array}{l}\text { Monetary equivalent } \\
\text { M }\end{array}$} \\
\hline & SELF & OTHER & SELF & OTHER & SELF & OTHER \\
\hline \multicolumn{7}{|l|}{ Study 1} \\
\hline Memory loss & -150 & -100 & 9.52 & 9.41 & 9.05 & 8.46 \\
\hline Depression & -147 & -77 & 8.65 & 8.52 & 8.37 & 7.68 \\
\hline Hallucination & -105 & -70 & 8.56 & 8.35 & 8.09 & 7.76 \\
\hline Speech disorder & -110 & -80 & 8.46 & 8.3 & 7.98 & 7.61 \\
\hline Insomnia & -70 & -39 & 6.27 & 5.9 & 6.41 & 5.98 \\
\hline Fever & -37.5 & -30 & 5.45 & 5.84 & 5.07 & 5.11 \\
\hline Dizziness & -30 & -20 & 5.28 & 4.7 & 5.12 & 4.17 \\
\hline Diarrhea & -30 & -21 & 4.76 & 4.89 & 4.68 & 4.5 \\
\hline Trembling & -30 & -21.5 & 4.55 & 4.46 & 4.6 & 4.28 \\
\hline Itching & -27 & -15 & 4.28 & 3.91 & 4.87 & 4.1 \\
\hline Flatulence & -25 & -10 & 4.16 & 3.78 & 4.05 & 3.52 \\
\hline Fatigue & -15 & -10 & 4.55 & 3.74 & 3.93 & 3.2 \\
\hline \multicolumn{7}{|l|}{ Study 2} \\
\hline Memory loss & -100 & -80 & 9.52 & 9.4 & 8.61 & 8.38 \\
\hline Depression & -90 & -68.5 & 8.65 & 8.07 & 7.4 & 6.8 \\
\hline Hallucination & -80 & -70 & 8.39 & 8.41 & 7.61 & 7.29 \\
\hline Speech disorder & -90 & -67 & 8.63 & 8.29 & 7.57 & 7.34 \\
\hline Insomnia & -40 & -32.5 & 6.53 & 5.92 & 5.79 & 5.49 \\
\hline Fever & -30 & -25 & 5.55 & 5.6 & 4.95 & 4.35 \\
\hline Dizziness & -25 & -20 & 5.11 & 5.05 & 4.43 & 4 \\
\hline Diarrhea & -20 & -20 & 5.15 & 4.56 & 4.77 & 3.88 \\
\hline Trembling & -20 & -15 & 4.45 & 4.36 & 4.19 & 3.44 \\
\hline Itching & -20 & -10 & 4.36 & 3.48 & 4.31 & 3.14 \\
\hline Flatulence & -15 & -14 & 4.19 & 3.41 & 3.75 & 3.12 \\
\hline Fatigue & -15 & -10 & 4.59 & 4.2 & 3.61 & 2.98 \\
\hline
\end{tabular}


A.3 Plots of search effort when including the outlier
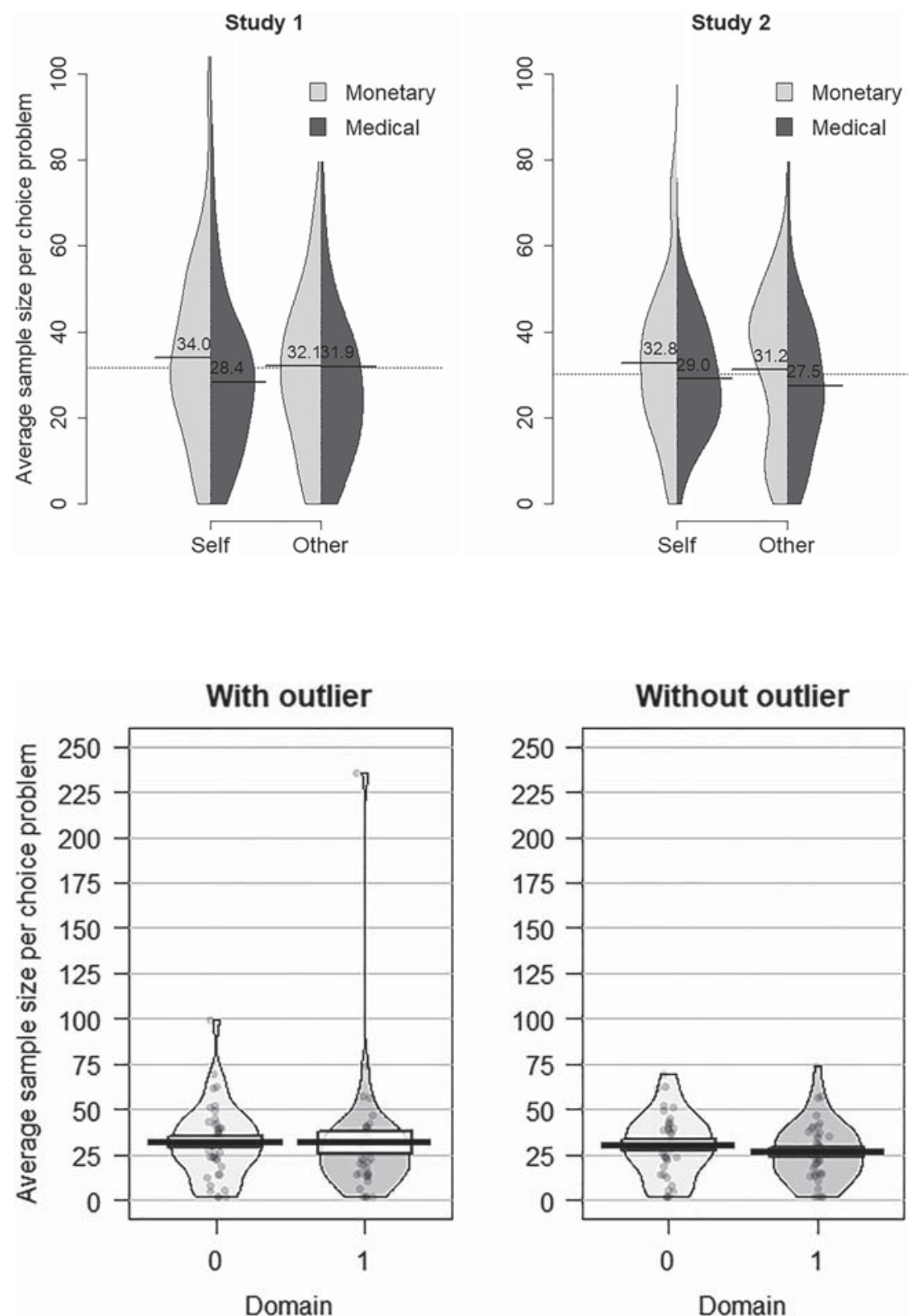

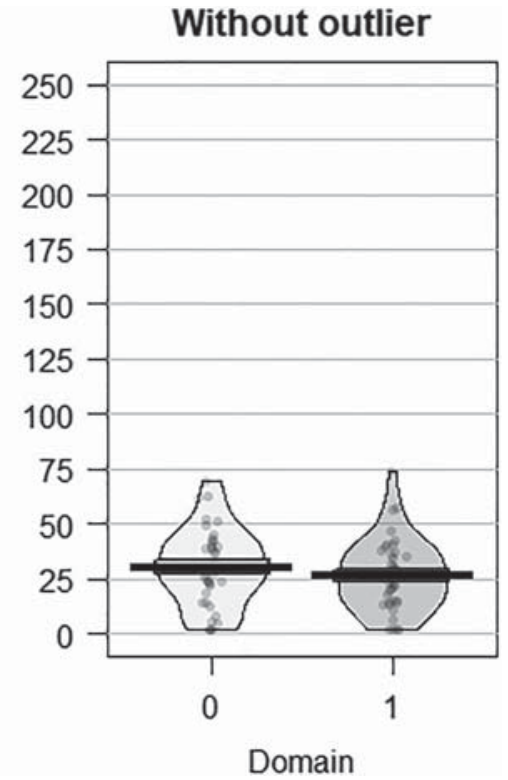

FIGURE A1 Average sample size per choice problem in the DfE condition before excluding the outlier in the OTHER condition of Study 1. With the outlier in the data set, the OTHER condition in Study 1 is the only condition where the difference in sample size between the monetary and medical domains disappears, $\chi^{2}(1)=1.66, p=0.197$
FIGURE A2 Average sample size per choice problem in the OTHER condition of Study 1 before excluding the outlier (left) and after excluding the outlier (right). Each point represents one participant, the upper and lower boarders of the box denote \pm 1 standard error from the mean (black line). Domain of 0 refers to the monetary and domain of 1 to the medical domain

\section{A.4 The effect of affect of the outcomes on search effort in each domain}

In order to examine the possible influence of affect on people's choices and search (in DfE) within the monetary domain and within the medical domain, we classified each gamble as being either affect-poor (mean affective rating below or equal to 5) or affect-rich (mean affective rating above 5). We then entered the dummy coded variable into a mixed-effects linear regression to test whether it predicts sample size, separately for the medical and monetary domains. As in the other analyses, we treated participants and choice problems as random effects and added decision perspective as control variable. Only in the monetary domain of Study 2 did the affective value of the gambles predict sample size, Study 1 monetary domain: $\chi^{2}(1)=1.52, p=0.218$; Study 1 medical domain: $\chi^{2}(1)=0.08, p=0.773$; Study 2 monetary domain: $\chi^{2}(1)=8.02, p=0.005$; Study 2 medical domain: $\chi^{2}(1)=0.53, p=0.467$. However, the effect was such that higher negative affect was associated with higher (rather than lower) search effort $(\beta=3.10)$. This does not support the assumption that people rely on smaller samples when making affect-rich decisions. 